\title{
Gonadal function in mink under artificial photoperiods
}

\author{
R. G. Gulevich, D. V. Klotchkov, L. N. Ivanova and L. V. Osadchuk \\ Institute of Cytology and Genetics, Siberian Branch of the Russian Academy of Sciences, \\ Lavrentyev Ave 10, Novosibirsk, Russia
}

\begin{abstract}
Exposure of juvenile minks to artificial light conditions imitating early autumn (additional illumination from 20 June to 20 July followed by $8 \mathrm{~h}$ daylight from 21 July to 10 October - photoperiod I; $8 \mathrm{~h}$ daylight from 21 July to 10 October - photoperiod II) induced the prolonged modification of sex steroid concentrations. The increase in plasma testosterone concentrations during the prepubertal period was followed by a decrease before and during the mating period in experimental males. The concentration of oestradiol in plasma increased just before the start of the mating period (January and February) in females under photoperiod I, and these hormonal changes were accompanied by an increase in fertility. The conditions of photoperiod II (involving fewer hours of daylight) had less effect on the sex steroid concentration in the blood of females, and fertility was not changed. The response of gonads to hCG injection at the beginning of puberty (November) was higher in males exposed to photoperiod I conditions and in females exposed to both photoperiods than in control animals.
\end{abstract}

\section{Introduction}

Reproduction in mink (Mustela vison) is characterized by features common to all mustelids and others unique to this species. The mating season is from late February to March. Male mink are sexually active throughout the breeding season. Female mink show prolonged oestrus, ovulation induced by mating and delayed implantation. The duration of diapause depends on the time of mating and the period from implantation to parturition is approximately 30 days. Parturition usually occurs between the last week in April and the middle of May.

The first breeding season starts at the same time as that of adults, but the time from first mating to parturition is greater for yearlings than for adults. The average litter size is smaller for first year females than for older females (Pilbeam et al., 1979).

The mink provides a useful model for investigation of photoperiodic regulation of seasonal reproduction, since it requires specific periods of daylight for the induction of gonadal activity. Male mink require short days to activate their reproductive system (Klotchkov and Kim, 1979; Boissin-Agasse et al., 1982; Martinet et al., 1992); however, maximum testes activity is observed in the period of increasing daylength (Onstad, 1967; Nieschlag and Bieniek, 1975; Pilbeam et al., 1979).

Photoperiod may be involved in the initiation of implantation in mink (Pearson and Enders, 1944; Murphy and James, 1974). Martinet et al. (1983) reports evidence that photoperiod influences implantation by means of changes in prolactin and progesterone concentrations.

Revised manuscript received 19 September 1994.
Our knowledge of the photoperiodic regulation of reproductive function and sexual development in mink is incomplete. Foster et al. (1985) report that female sheep, seasonal breeders, require short days to activate their reproductive system at puberty. These authors suggest that photoperiod controls pulsatile LH secretion through modulation of the GnRH pulse generator by internal cues (for example, melatonin). During pubertal transition, the LH pulse frequency increases, thereby inducing successful completion of the first follicular phase culminating in ovulation.

The stimulating effect of short daylength during early ontogenesis (summer-autumn) in spermatogenesis in mink from October to November has been shown. This effect is enhanced by an additional month-long illumination before the short day period (Klotchkov et al., 1985). However, little is known about the consequences of early artificial photoperiodic conditions on endocrine gonadal function and fertility in adult mink. It can be assumed that artificial photoperiods modify the endocrine system regulating sexual development by affecting the concentrations of sex steroids, and gonad responsiveness to gonadotrophin.

The purpose of the present study was to investigate the influence of short day photoperiodic conditions during early ontogenesis on the development of endocrine gonadal function and reproductive performance in mink.

\section{Materials and Methods}

\section{Animals}

The investigations were carried out on mink (Mustela vison) bred at the Experimental Fur Farm of the Institute of Cytology 
and Genetics, Siberian Branch of the Russian Academy of Sciences (Novosibirsk). All animals were fed the standard farm ration.

Two experiments were carried out over two years. Each experimental group consisted of 60 animals. In the first experiment, ten females and ten males were chosen randomly each month and blood samples were collected. In November and March, animals from each group were killed for in vitro investigation and determination of masses of gonads and uteri. Average numbers in November: 30 males; 10 experimental females and 18 control females; in March: 15 males and 10 females. In the second experiment, groups of ten animals, including the control, were injected with hCG in November. The vaginal smears were analysed in all experimental females in October, December and January. Litter size was recorded in all mink after parturition.

A common commercial breeding strategy in Russia has been to mate females early in the breeding season (during the first week of March) and mate them again after 7 or 8 days. Both experimental and control females were placed with control males on various dates from I March and, if mating took place, females were allowed to mate again on the next day (the first mating period). Females were placed with the same males 7-8 days later, and allowed to mate once more on the next day (the second mating period). If females were not receptive during the first exposure to males, they were allowed to mate every day until mating occurred and the breeding scheme was then continued as described above. Some females mated only once during the first or second mating period, or within a single mating period. Some mated only once in the breeding season.

\section{Photoperiods}

Two photoperiods imitating early autumn were used (Fig. I). Photoperiod I consisted of additional illumination from 20 June to 20 July, followed by short days from 21 July to 10 October (animals of Group I). Photoperiod II consisted of short days from 21 July to 10 October (animals of Group II). The control animals were maintained under natural daylength conditions. The additional illumination was provided by incandescent $200 \mathrm{~W}$ lamps from 17:30 to 09:30 $\mathrm{h}$. The intensity of illumination at the cage bottom was $200 \mathrm{~lx}$. For short daylength, opaque polyethylene blinds were down at 17:30 and up at 09:30. Ventilators maintained the air conditions and temperature at the control values.

\section{Procedures}

Mink were restrained in small cages and blood samples were taken from the top of the tail without anaesthesia between 09:00 and 12:00 h. Samples were collected each month from June (males) or July (females) to March.

The response of gonads to hCG was investigated in vivo, by a single injection of $100 \mathrm{U} \mathrm{kg}^{-1}$ i.m. in November. Animals were killed by cervical dislocation 7 days after injection and weighed; blood samples were collected and the testes or uteri and ovaries were weighed.

Blood samples were centrifuged for $1500 \mathrm{~g}$ for $10 \mathrm{~min}$ and plasma was frozen and stored at $-18^{\circ} \mathrm{C}$ until the hormone assays. The testes were incubated as described below.
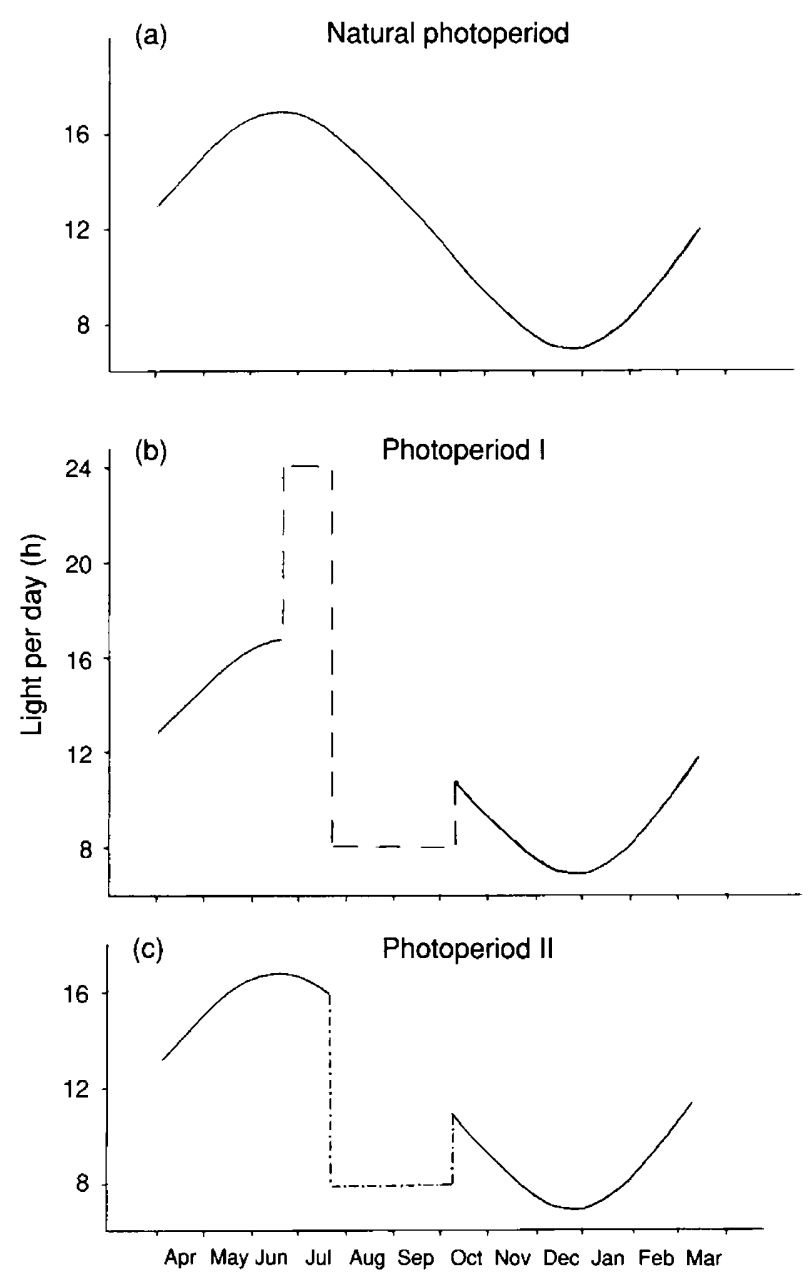

Fig. 1. Design of experimental photoperiods: (a) natural photoperiod; (b) photoperiod I - additional illumination from 20 June to 20 July followed by short days from 21 July to 10 October; (c) photoperiod II - short days from 21 July to 10 October.

\section{Incubation in vitro}

The males were killed, and the gonads weighed, sliced and placed into $5 \mathrm{ml}$ of Krebs-Ringer bicarbonate buffer containing $11 \mathrm{mmol}$ glucose $1^{-1}$, and then incubated for $3 \mathrm{~h}$ at $37^{\circ} \mathrm{C}$. The buffer was presaturated with a gas mixture of $95 \%$ oxygen and $5 \%$ carbon dioxide ( $\mathrm{pH} 7.4$ ). The medium was then collected and frozen.

\section{Radioimmunoassay}

Steroid hormones in plasma and gland incubates were determined by radioimmunoassays using kits produced by Cea-Ire-Sorin (Gif-sur-Yvette, St Quentin Yvelines) after extraction with ethyl ether. The extraction yield was 0.9-1.0. The sensitivity of the assays expressed as the minimum detectable amount of hormone was $2.5 \pm 1.2 \mathrm{pg}$ per tube for testosterone and $1.0 \pm 0.2 \mathrm{pg}$ per tube for oestradiol. The intra-assay and interassay coefficients of variation were $9 \%$ and $3 \%$, respectively, for oestradiol and $5 \%$ and $6 \%$ for testosterone. 


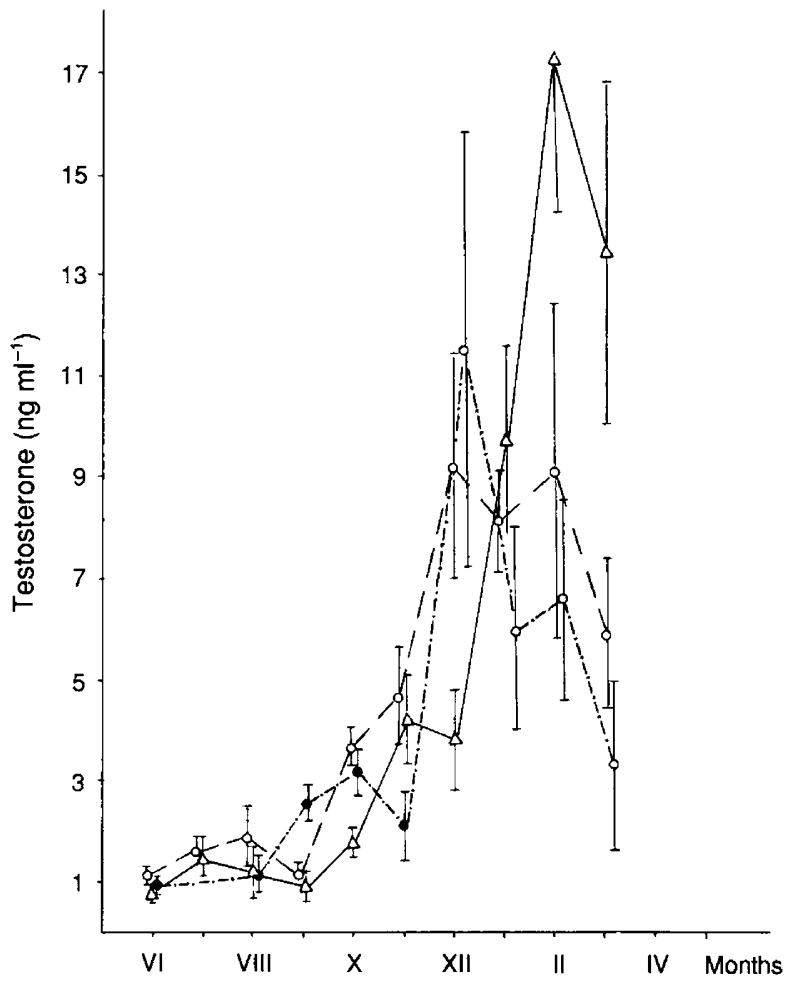

Fig. 2. Effect of artificial photoperiods on the concentration of testosterone in plasma of male mink. (-) Control animals; (- - ) Group exposed to photoperiod I; $(-\cdot-\cdot-)$ Group exposed to photoperiod II. Photoperiod I: additional illumination from 20 June to 20 July followed by short days from 21 July to 10 October; photoperiod II: short days from 21 July to 10 October.

\section{Statistical analyses}

All values are means \pm SEM. The data obtained for the plasma hormone concentrations were subjected to one- or two-way analyses of variance (test F MANOVA). The data for the hormone content of the gonad incubates, fertility, and relative gonad and uterine masses were analysed using Student's $t$ test. The percentage of females mated only during the first mating period, barren, or with signs of oestrus were analysed by $\varphi$-test.

\section{Results}

\section{Males}

The testosterone concentrations in the control males increased during the period of the investigation and reached maximum values before the mating period in February and remained at that concentration during March (Fig. 2). The artificial light conditions produced a significant increase in the plasma testosterone concentration in Group I animals in October $(P<0.01)$ and in Group II animals in September $(P<0.01)$ and October $(P<0.05)$.

In both groups of experimental animals, the maximum testosterone concentration was also detected before the mating period, but earlier than in controls (December). However, the
Table 1. Effect of artificial photoperiod on the relative testicular mass of, and in vitro testosterone production (ng per $100 \mathrm{mg}$ $\mathrm{h}^{-1}$ ) by, testes in mink

\begin{tabular}{|c|c|c|c|}
\hline & Control & Photoperiod I & Photoperiod II \\
\hline \multicolumn{4}{|c|}{ Relative testicular mass } \\
\hline November & $\begin{array}{l}0.77 \pm 0.07^{\mathrm{a}} \\
(26)\end{array}$ & $\begin{array}{l}1.66 \pm 0.16^{b} \\
\text { (29) }\end{array}$ & $\begin{array}{l}1.01 \pm 0.11 \\
\quad(39)\end{array}$ \\
\hline March & $\begin{array}{c}3.64 \pm 0.16 \\
(17)\end{array}$ & $\begin{array}{l}3.26 \pm 0.22 \\
\text { (I4) }\end{array}$ & $\begin{array}{l}3.08 \pm 0.42 \\
\quad(15)\end{array}$ \\
\hline \multicolumn{4}{|c|}{ In vitro testosterone production by testes } \\
\hline November & $\begin{array}{c}14.77 \pm 4.91 \\
(10)\end{array}$ & $\begin{array}{c}12.79 \pm 2.27 \\
(9)\end{array}$ & $\begin{array}{c}9.97 \pm 3.36 \\
(9)\end{array}$ \\
\hline March & $\begin{array}{c}48.91 \pm 9.90^{\mathrm{a}} \\
(8)\end{array}$ & $\begin{array}{c}12.39 \pm 7.10^{\mathrm{b}} \\
(5)\end{array}$ & $\begin{array}{c}11.33 \pm 2.97^{\mathrm{b}} \\
(5)\end{array}$ \\
\hline
\end{tabular}

Values are means \pm SEM.

a.b Values are significantly different $(P<0.05)$.

Number of animals is shown in parentheses.

Relative testicular mass $=$ testis mass/body mass.

maximum testosterone concentrations in experimental mink failed to reach those observed in the controls. The hormone concentrations in the males of Group I in December were significantly higher than those of the control animals $(P<0.05)$. In February and March they were found to be lower in Group II animals than in the controls $(P<0.01$ and $P<0.05$, respectively).

There were no significant differences in testosterone production by testes in November between experimental and control groups in vitro, whereas this was significantly lower in both experimental groups by comparison with controls in March (Table 1).

The relative masses of testes (testes mass/body mass) in November were higher in Group I than in control animals (Table 1).

Injection of hCG to male minks of all groups did not significantly influence the plasma testosterone concentration, testosterone production by testes or relative testicular mass (Fig. 3). Although the plasma testosterone concentrations of Group I untreated animals did not differ significantly from those of the intact controls, after hCG injection concentrations were significantly higher than those of the control animals (Fig. 3). This was also true for testosterone production in vitro by testes in Group I animals, which was significantly higher in males after hCG injection than in the controls (Fig. 3). Relative mass of testes was also significantly higher in Group I animals than in controls after hCG injection (Fig. 3).

\section{Females}

The artificial light conditions consisting of additional illumination, followed by short daylength (photoperiod I) influenced the oestradiol concentrations in plasma of females (Fig. 4). Although the changes were not always stable, an increase of the oestradiol concentration in August $(P<0.05)$ and September $(P<0.01)$ was observed (i.e. during the period of short daylength); however, the hormone concentration decreased after abandoning shortened daylength in October 

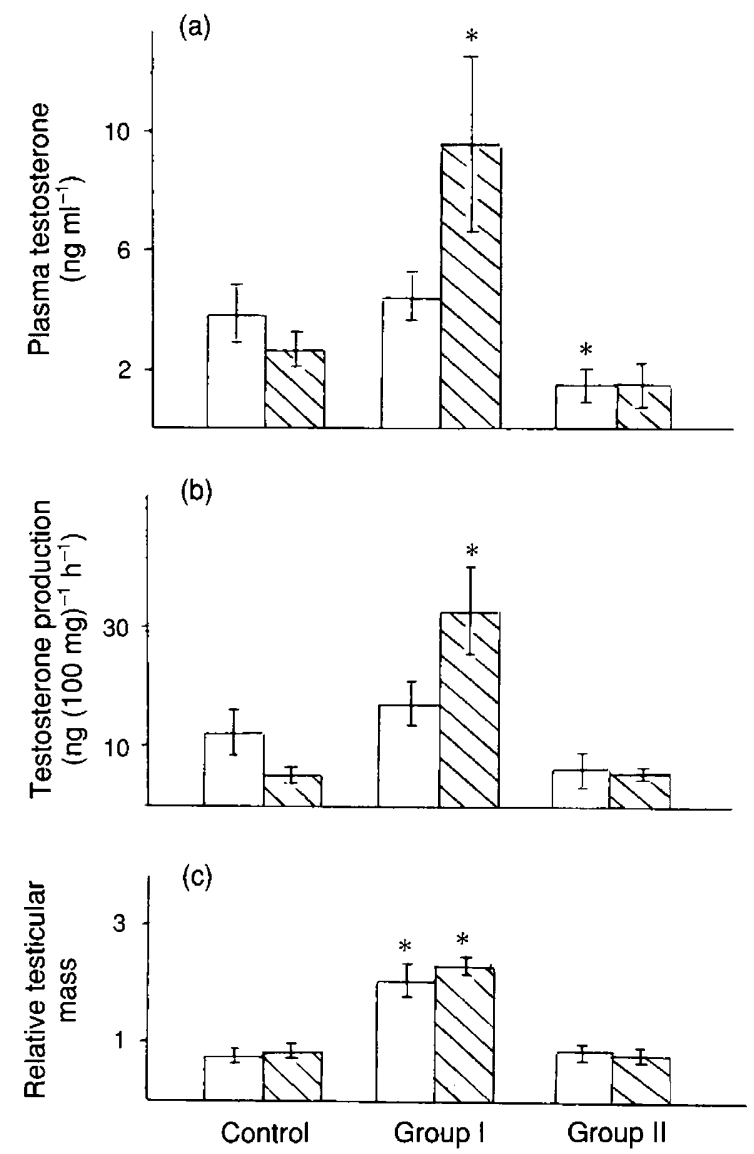

Fig. 3. Effect of hCG injection on (a) plasma testosterone, (b) testicular production of testosterone and (c) relative testicular mass in male mink in different photoperiods. *Significant difference $(P<0.05)$ between animals of Groups I or II and controls (intact ( $\square$ ) or after hCG treatment $(\mathbb{\otimes})$ ).

$(P<0.05)$ and November $(P<0.05)$ as compared with the controls. During January and February, the oestradiol concentration rose again in animals of Group I relative to concentrations in controls $(P<0.01$ and $P<0.05$, respectively).

The relative masses of uteri (uterus mass/body mass) were three times higher in females of Group I than in the control animals in November (Table 2). In Group I animals, the percentage of females with signs of oestrus, as indicated by vaginal smears, was greater than that of control females in October and December (Table 3).

The short daylength conditions of photoperiod II had less effect on reproductive function and oestradiol concentrations in female mink than did photoperiod I (Tables 2 and 3; Fig. 4). The hormone concentration increased in August $(P<0.01)$ compared with that observed in control animals, i.e. one month after implementation of the short days. However, in October, it became lower than in the control animals $(P<0.01)$.

Injections of hCG into females in November produced an increase in the relative uterine masses in animals of all groups and the relative ovarian masses in Group I animals (Fig. 5). The oestradiol concentrations at this time, in treated females of Groups I and II, were significantly higher than those in treated control animals (Fig. 5).

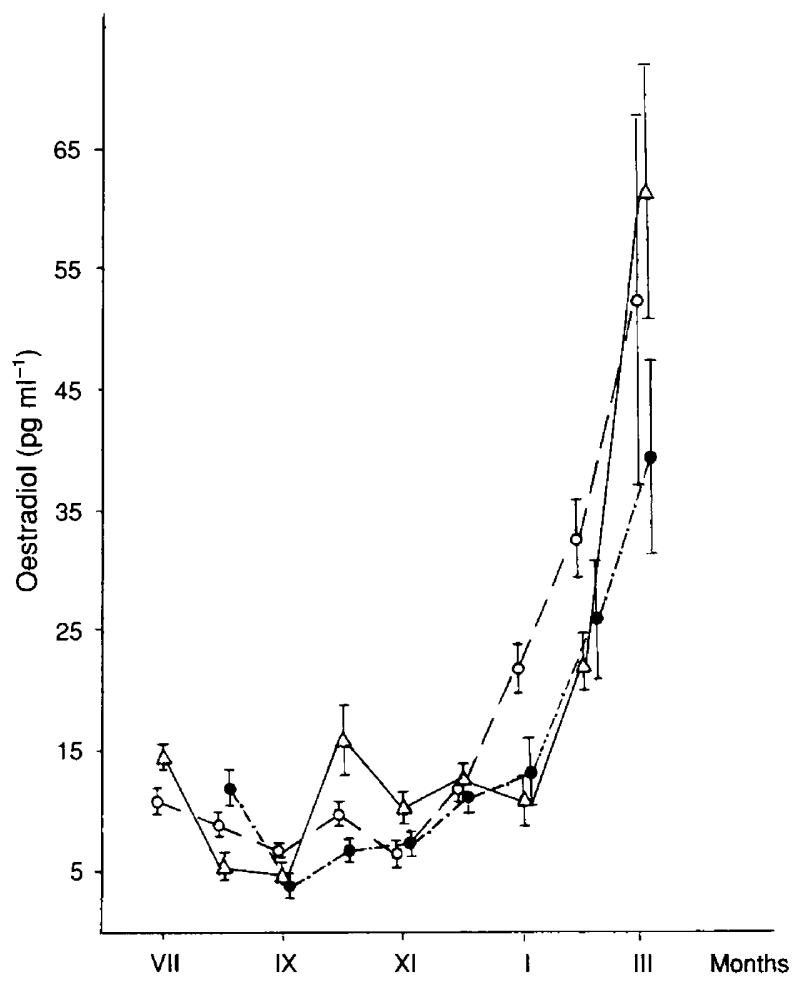

Fig. 4. Effect of artificial photoperiods on the concentration of oestradiol in plasma of female mink. ( $\longrightarrow$ Control animals; $(---)$ Group exposed to photoperiod I; $(-\cdot-\cdot-)$ Group exposed to photoperiod II.

Table 2. Effect of artificial photoperiod on the relative masses of mink ovaries and uteri

\begin{tabular}{lccc}
\hline & Control & Photoperiod I & Photoperiod II \\
\hline Ovaries & & & \\
November & $0.12 \pm 0.01$ & $0.13 \pm 0.01$ & $0.11 \pm 0.01$ \\
& $(18)$ & $(9)$ & $(8)$ \\
March & $0.14 \pm 0.01$ & $0.16 \pm 0.02$ & $0.12 \pm 0.02$ \\
& $(10)$ & $(8)$ & $(9)$ \\
Uteri & & & $0.11 \pm 0.01$ \\
November & $0.11 \pm 0.01^{\mathrm{a}}$ & $0.35 \pm 0.03^{\mathrm{b}}$ & $(8)$ \\
March & $(18)$ & $(9)$ & $0.38 \pm 0.05$ \\
& $0.48 \pm 0.02$ & $0.50 \pm 0.04$ & $(9)$ \\
& $(10)$ & $(8)$ & \\
\hline
\end{tabular}

Values are means \pm sem.

a,b Values are significantly different $(P<0.05)$.

Number of animals is shown in parentheses.

Relative masses: masses of ovaries (or uteri)/body mass.

The percentage of females mated during the first mating period was higher in both experimental groups than in the control (Table 4). The number of infertile females did not differ between the control and experimental groups (Table 4). Fertility (litter size per whelping female) was significantly higher in Group I females than in the control animals (Table 5). The duration of pregnancy was the same in experimental and control groups (Table 5). 
Table 3. Effect of artificial photoperiod on the number of female mink with signs of oestrus before the mating season

\begin{tabular}{lccc}
\hline & Control & Photoperiod I & Photoperiod II \\
\hline October & & & \\
Total & 60 & 32 & 27 \\
With oestrus & 0 & 4 & 1 \\
& $(0 \%)^{\mathrm{a}}$ & $(12.5 \%)^{\mathrm{b}}$ & $(3.7 \%)$ \\
December & & & \\
$\quad$ Total & 211 & 32 & 30 \\
With oestrus & 57 & 19 & 6 \\
& $(27.0 \%)^{\mathrm{b}}$ & $(58.4 \%)^{\mathrm{c}}$ & $(20.0 \%)$ \\
January & & & \\
Total & 225 & 20 & 20 \\
With oestrus & 199 & 17 & 15 \\
& $(88.4 \%)$ & $(85.0 \%)$ & $(75.0 \%)$ \\
\hline
\end{tabular}

a.b.c. Values with different superscripts are significantly different $(P<0.05)$.

(a)

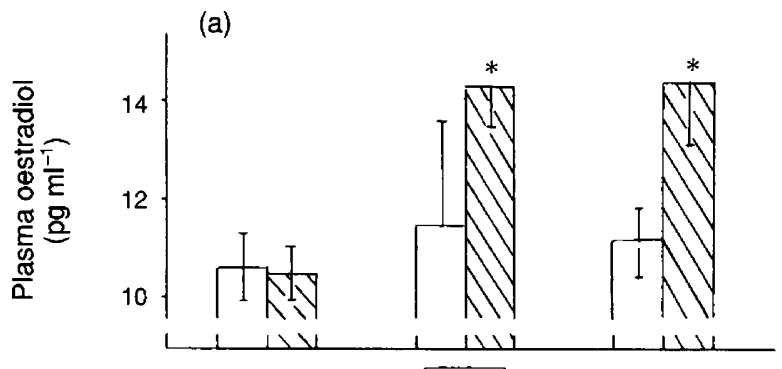

(b)

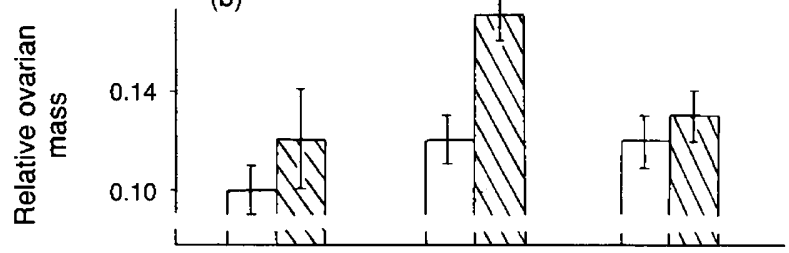

(c)

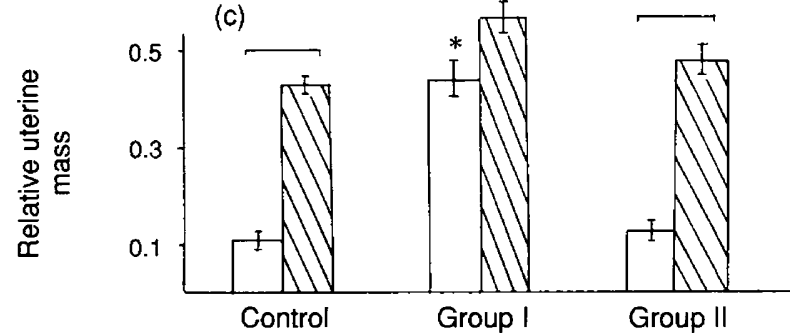

Fig. 5. Effect of hCG on oestradiol concentration in plasma and relative uterine and ovarian masses in female mink in different photoperiods. *Significant difference $(P<0.05)$ between animals of Groups I or II and controls (intact $(\square)$ or after hCG treatment $(\mathbb{Q})$ ); $\longrightarrow$ Significant difference $(P<0.05)$ between intact and hCG-treated animals.

\section{Discussion}

The results presented here indicate that hormone changes in male mink occur as a result of artificial photoperiodic conditions. The conditions of both experimental photoperiods
Table 4. Effect of artificial photoperiod on the number of female mink that mated only once or were infertile

\begin{tabular}{lccc}
\hline & Control & Photoperiod I & Photoperiod II \\
\hline $\begin{array}{l}\text { Total } \\
\begin{array}{l}\text { Mated only } \\
\text { during the } \\
\text { first mating } \\
\text { period }\end{array}\end{array}$ & 183 & 103 & 23 \\
& 25 & & \\
Total & $(13.6 \%)^{\mathrm{a}}$ & $(57.3 \%)^{\mathrm{b}}$ & $(69.6 \%)^{\mathrm{b}}$ \\
Infertile & 552 & 103 & 23 \\
& 106 & 14 & 2 \\
& $(19.2 \%)$ & $(13.6 \%)$ & $(8.7 \%)$ \\
\hline a.b Values with different superscripts are significantly different $(P<0.05)$.
\end{tabular}

Table 5. Effect of artificial photoperiod on some parameters of reproductive function in female mink

\begin{tabular}{lccc}
\hline Parameter & Control & Photoperiod I & Photoperiod II \\
\hline $\begin{array}{l}\text { Duration of } \\
\text { pregnancy } \\
\text { (days) }\end{array}$ & $\begin{array}{c}48.6 \pm 0.4 \\
(137)\end{array}$ & $\begin{array}{c}49.3 \pm 0.7 \\
(89)\end{array}$ & $\begin{array}{c}50.9 \pm 1.3 \\
(21)\end{array}$ \\
$\begin{array}{l}\text { Litter size } \\
\text { per whelping } \\
\text { female }\end{array}$ & $\begin{array}{c}5.14 \pm 0.09^{\mathrm{a}} \\
(445)\end{array}$ & $\begin{array}{c}6.66 \pm 0.19^{\mathrm{b}} \\
(86)\end{array}$ & $\begin{array}{c}4.90 \pm 0.38 \\
(20)\end{array}$ \\
\hline
\end{tabular}

Values are means \pm SEM.

a.bValues with different superscripts are significantly different $(P<0.05)$.

Number of animals is shown in parentheses.

stimulated the endocrine function of mink testes in the autumn and in the early winter (i.e. during prepubertal and pubertal periods, respectively; Onstad, 1967). The relative mass of testes in November was higher in males of Group I and tended to be higher in males of Group II than in the control animals. Furthermore, photoperiodic stimulation in Group I males was accompanied by an increase in endocrine response of the gonads to hCG action. The data obtained suggest that photoperiod I influences endocrine function of the testes in November more than in photoperiod II.

The capacity of the gonads to secrete steroids in response to gonadotrophin stimulation depends on the number of $\mathrm{LH}$ receptors in gonads (Ryan, 1985). Therefore, it is possible that the enhancement of the gonad response to hCG in mink in experimental photoperiod I results from greater numbers of such receptors.

Martinet et al. (1992) reported an increase in concentrations of FSH and LH in serum, and a regrowth of testes in male mink in a photoperiod similar to that used in the present study (photoperiod II). The increase in plasma testosterone concentrations in Group II juvenile male mink after maintenance under short daylength conditions during summer is in agreement with the significant rise in concentrations of gonadotrophins and testes masses in adult males reported by Martinet et al. 
(1992). Therefore, it is likely that short days stimulate the hormonal activity of testes through their influence on hypophysial gonadotrophins.

The activation of endocrine function of the testes in autumn and early winter under the influence of both experimental photoperiods was accompanied by its suppression just before and during the mating period. This finding correlates well with the results of histological evidence for the activation of spermatogenesis in October (Klotchkov et al., 1985) and its suppression in March (Torgoon et al., 1984) under the same experimental conditions.

The artificial light conditions of photoperiod I stimulated the reproductive system of female mink during puberty as evidenced by the relative masses of uteri and the composition of vaginal smears. This activation of the reproductive system in females was accompanied by an increase in the oestradiol concentration and an enhancement of the response of the ovaries to hCG.

The activation of the female reproductive system under the influence of photoperiod I could result in earlier onset of the mating period, which might explain why most experimental females mated only during the first mating period, in contrast to the control ones.

The reproductive system of females and males was activated under photoperiod I in November, but there were differences between males and females in the reaction of endocrine gonadal function in February. The endocrine function of testes decreased in this period, while the endocrine function of ovaries was greater than that in the control animals, i.e. the female reproductive system remained activated longer than the male system. The differences between the sexes in serum LH and FSH patterns have been observed in hamsters exposed to short photoperiods (Goldman and Brown, 1979). An increase in plasma LH has been observed just before the start of the mating season in stallions earlier than in mares (Ortavant et al., 1985). Hence, the differences between the sexes in the response of the endocrine function of mink gonads to photoperiod I observed in February may be due to sexual dimorphism in the development of reproductive function and of LH and FSH secretion patterns.

In the present study, the fertility of Group I females was higher than that of control animals. It is likely that earlier or stronger activation of the sexual system in females under photoperiod I results in an increase in ovulation rate or more favourable pregnancy conditions. The conditions of photoperiod I may accelerate the sexual development of female mink and, as a consequence, increase their fertility.

In conclusion, the conditions of artificial photoperiods, including short daylength during early ontogenesis, can cause the modification of the hormonal regulation of sexual development in mink as demonstrated by changes in the concentration of sex steroids and the response of gonads to hCG injection.

The authors thank A. A. Kim, N. G. Morosova and T. M. Puchkova for excellent technical assistance, A. I. Zhelesova for her advice and J. K. Sabelfeld for help in the preparation of the manuscript.

\section{References}

Boissin-Agasse L, Boissin J and Ortavant R (1982) Circadian photosensitive phase and photoperiodic control of testes activity in the mink (Mustela vison), a short day mammal Biology of Reproduction 26 110-119

Foster DL, Yellon SM and Olster DH (1985) Internal and external determinants of the timing of puberty in the female Journal of Reproduction and Fertility 75 $327-344$

Goldman B and Brown S (1979) Sex differences in serum LH, FSH patterns in hamsters exposed to short photoperiod Joumal of Steroid Biochemistry 11 1B 531-535

Klotchkov DV and Kim AA (1979) The effect of photoperiod on sexual function in male minks of different genotypes Agricultural Biology 14 66-70 (in Russian)

Klotchkov DV, Gulevich RG, Osadchuk LV and Kim AA (1985) The photoperiodic programming of the gonad's endocrine function and spermatogenesis in young mink Journal of General Biology 46 679-685 (in Russian)

Martinet L, Allain D and Mellnier M (1983) Regulation in pregnant mink (Mustela vison) of plasma progesterone and prolactin concentrations and regulation of onset of the spring moult by daylight ration and melatonin injections Canadian Joumal of Zoology 61 1959-1963

Martinet L, Mondain-Moval M and Monnerie R (1992) Endogenous circannual rhythms and photorefractoriness of testis activity, moult and prolactin concentrations in the mink (Mustela vison) Journal of Reproduction and Fertility $95325-338$

Murphy BD and James DA (1974) The effect of light and sympathetic innervation to the head on nidation in mink Journal of Experimental Zoology $187267-276$

Nieschlag E and Bieniek H (1975) Endocrine testicular function in mink during the first year of life Acta Endocrinologica 79 375-379

Onstad O (1967) Studies on postnatal testicular changes, semen quality and anomalies of reproductive organs in the mink Acta Endocrinologica Supplementum 11755 I-117

Ortavant R, Pelletier J, Ravault JP, Thimonier J and Volland-Nail P (1985) Photoperiod: main proximal and distal factor of the circannual cycle of reproduction in farm mammals Oxford Reviews of Reproductive Biology 7 305-345

Pearson OP and Enders RK (1944) Duration of pregnancy in certain mustelids Journal of Experimental Zoology 95 21-25

Pilbeam TE, Concannon PW and Travis HF (1979) The annual reproductive cycle of the mink (Mustela vison) Journal of Animal Science 48 578-584

Ryan KD (1985) Maturation of ovarian function in female ferrets influenced by photoperiod Journal of Reproduction and Ferility 74 503-507

Torgoon PM, Mostovaja LK, Cirjanidi OW, Klotchkov DV, Kim AA and Gulevich RG (1984) Morphofunctional changes of testes in standard minks under different photoperiodic conditions. In Profilactica $i$ Therapia Infectionnych $i$ Nesarasnych Bolesney Zhyvotnych o Chozjastvach ZChS pp 111-116 Ed. BT Artemov. Sbornic Nautchnych trudov Voronezhskogo Selskochosjastvennogo Instituta, Voronezh (in Russian) 